\title{
ENTREPRENEURSHIP AND ETHICS IN SMALL AND MEDIUM SIZE ENTERPRISES: LITERATURE ANALYSIS
}

\author{
Daniel RUSU ${ }^{a *}$, Doriana SANDU ${ }^{b}$ \\ ${ }^{a, b}$, Bucharest University of Economic Studies, Romania
}

DOI: $10.24818 / \mathrm{IMC} / 2020 / 03.21$

\begin{abstract}
There is undoubtedly a growing pressure on SMEs to develop ethical behavior. Entrepreneurs have become increasingly attentive and demanding to the reputation of the business they run. From this point of view, micro and small and medium enterprises have become some of the companies that are influenced because they do not have specific relevant connections, data, information and financial resources and intangible assets to implement as many ethical practices as possible. It becomes very clear that for SMEs it is a luxury to avoid the implementation of ethics in business. Employment priority is the main solution to most of the problems facing the economy (eliminates unemployment, allows the use of human capital more efficiently, minimizes the problem of social exclusion, etc.). As the research of business ethics as well as the research of entrepreneurship become more and more established, the intersection between entrepreneurship and ethics will receive more and more attention. As the research of business ethics as well as the research of entrepreneurship become more and more established, the intersection between entrepreneurship and ethics will receive more and more attention.
\end{abstract}

KEYWORDS: business ethics, entrepreneurship, ethics, SMEs.

\section{INTRODUCTION}

Over the past few decades, significant and growing scientific interest in entrepreneurs and the creation of new risks have resulted in the formation of entrepreneurship as a rigorous academic field of study, including the creation of several dedicated academic journals, changing business curricula and increasing research conferences on the topic. In a similar way, the field of business ethics - including both the study of ethical behavior and the societal impact of for-profit companies - has gained recognition and legitimacy in the last two decades as a rigorous and important field of study.

How could the theoretical frameworks of the other enrich the ideas in one discipline? All these questionnaires (but also others) come from a growing literature that is at the intersection of entrepreneurial research and business ethics scholarship. This growing research direction highlights the relevance of each of the academic fields in question. For example, entrepreneurship researchers emphasize the importance of entrepreneurial ethics for the global economy (Ceptureanu \& Ceptureanu, 2019a), and ethics researchers advocate a greater empirical focus on small and emerging firms, rather than large organizations, in ethical research (Spence \& Van Heekeren , 2005).

Understanding these different areas of inquiry provides an inclusive picture of a growing research agenda on topics linking ethics and entrepreneurship in various ways. Modern enterprises employ people who come from many social structures and who differ from each other through a whole series of things related primarily to the social environment they come from, their education, age, religious affiliation or country of origin, etc. All these employees of the companies, when they are hired, will

\footnotetext{
${ }^{*}$ Corresponding author. E-mail address: rusumdaniel@gmail.com
} 
undoubtedly bring in those companies a lot of mentalities, goals and their own, specific values. All this whole picture, which is characterized by a great diversity, will produce ethical influences not only on the individual level of the employee but also for managers (Abiodun \& Oyeniyi, 2014). Businesses have realized that ethical deviations can be very costly for society as a whole and not just for the organization (Abiodun \& Oyeniyi, 2014). Moreover, today's managers have become increasingly aware of the reputation of the business they own. It is noteworthy that SMEs, which have played a leading role in business in recent decades, have been left out of the concepts of review on ethics present in current business.

\section{ETHICS IN ENTREPRENEURSHIP}

Two aspects need to be differentiated to discuss business ethics. Ethics present in business is defined as an alternative to professional ethics - classified as a subcategory of that ethics and studied by researchers in institutions, researchers in academia and by ethics professionals - shows differences from business ethics perceived as the habit of taking over in the business world a conduct based on ethics. In the institutional sense, the existence of business ethics is, for example, highlighted by publications on this topic or by academic lectures on ethics. Naturally, it does not necessarily transpose the theoretical or philosophical value of these actions.

Putting ethics into practice in entrepreneurship in the business environment as well as the significance of business ethics can be analyzed taking into account the following three arguments: 1 . Intrinsic entrepreneurship is not evaluated from an ethical point of view as an the practice that is subject to the influence of the principles generated by the supply but also by the demand. 2. The activities undertaken by enterprises in the contemporary world of globalization are process-constrained activities over because only one company does not have a current, because they take place on a global scale. 3. An exact definition of the respective title is not identified in the commercial activity (we are obliged to take into account the fact that the expression related to the subject is taken into account considering the popular mentality).

All these arguments are based on the obvious difference that exists between a company and an entrepreneur. This aspect is of special importance when we consider the variants for which we can apply in business ethics and we do not show the due attention due to this differentiation as well as the implementation in business of the ethical business behavior. The difference between an entrepreneur and an enterprise, predominantly, consists in the different purposes of activity. The entrepreneurial target is to get a profit from the sale of goods while the goal of a business is to produce those goods. For example, for a company, a target may be to produce shoes or any other object of footwear and the target that an entrepreneur has may be to obtain exclusively profit from this type of commercial activity.

The increase in a special way of the production is due to an increase of the demand for the respective products and a decrease of the volumes of manufactured products is due exclusively to the decrease of the demand for the respective products. The bankruptcy of some companies, the emergence of certain social groups impoverished and without social perspectives, the growth of the population segment that has no job in any form are determined primarily by a decrease in the free market demand for products and services specific. In general, as an ethic of business life and activity is presented in the literature business ethics as such or the ethics of an enterprise. Also, the term business ethics can be defined in the broadest possible terms.

For example, notions like ethical attributes of entrepreneurs, employee-employer relations, principles of peace or democracy, acceptance of human dignity, etc. are particularly interesting for business ethics. Obviously, it is particularly necessary and important at the same time to be able to frame the specificity of the character of ethics in business in such a way that we can never doubt the need to implement those ethics. During the prosperity period, the obligations contained in the codes of ethics are respected. But, in crisis situations, in which human relations become objectified, only survival 
and profit matter and consciousness is ultimately forgotten, no ethics apply. Within a defined reality of work submitted in order to obtain the highest profit, the highest economic performance and most of the time and at any price paid in a fierce and particularly strong competition on the market, no one can be found. kind of excuse or justification for entrepreneurs regarding ethical conduct.

Moreover, companies that respect their entrepreneurs carrying out their business taking into account customer requirements as well as ethical principles risk economic losses and, therefore, termination of business. If, taking into account the rules but also the regulations provided by ethics, the action is not in any way effective and possible, according to Putnam (2016) the consequences arising from such decisions must be taken into account. Consequently, this aspect generates finalities but also situations that manifest themselves in a way contrary to a certain specified institutional ethics and whose main objectives are represented precisely by the initiation as well as by the maintenance of the respective principles.

The ethics present in the business environment represents an assumed and common ethical system and from this point of view it generates and manifests without a doubt a specific ethics. First of all, it uses with priority to avoid the use of so-called moral diseases as well as to avoid the use of certain practices that are not human. Undoubtedly, the establishment and use of moral principles such as compliance with the word, contracts, recourse to negotiations is a possible solution to implement.

The family, school, university, and workplace should be involved in this process. Maybe this is where the work should start - the basics that need to be learned, so that the attitude of future potential entrepreneurs towards ethics is different.

\section{ASPECTS OF ETHICS IN THE ACTIVITY OF SMES}

Ethics itself refers to a set of rules of behavior or to a well-defined framework of principles of a moral nature that involve the correct realization of things (Ceptureanu \& Ceptureanu, 2019a). Ethics represents that part of philosophy that establishes in a manner of a theoretical, rational, assumed but also reasonable nature the correctness, the good, the morality but also correct from unjust behaviors and actions. Ethical behavior involves doing, morally, what is right (Ceptureanu et al., 2019c; Okafor, 2011; Riley, 2012). Ethics is supported by fundamental, general and solid principles of fairness and integrity, being channeled on the environment of responsibility and the local community, but also on internal issues of stakeholders, such as employee benefits and salaries, customer satisfaction, product quality.

Also, ethics is a bunch of virtues and rules that channel and perpetuate behavior. Therefore, ethics are principles of a moral nature that can define the representative behavior of an individual or the behavior of a group. Many scholars have generally established that ethics defines a specific framework of values, rules but also of principles that guide but also characterize the conduct of various segments and sets as well as of the people present in a society or a company. In the business environment, ethics pragmatically represents the research of the parameters that define morality as well as the conduct in the business environment. The ethics present in business is precisely the application of ethics in the field of business practices. Defines in the most specific way the implementation of the general regulations of ethics in the particular framework that characterizes business behavior (Herteliu et al., 2019). Ethics present in the business environment refers to an ethical or unethical attitude and behavior of an employee or manager within an organization and varies from one culture to another, from one situation to another, from one person to another. On the other hand, the ethics present in the business environment can represent as a group of values and principles of a moral nature that lead the organization's behavior on principles of correctness or error. Obviously, the ethics present in the business environment presupposes the way in which a commercial activity incorporates essential values such as fairness in its practices, policies and decision making, but also respect, trust and honesty (Hellriegel et al., 2008). According to Rossouw (2004), business ethics refers to the identification, but also to the implementation of standards of conduct to ensure 
and certify that an enterprise cannot negatively influence the benefits of stakeholders. Ethical practices refer to the conscious observance of the standard of morality that directs an individual but also a business to follow certain rules of conduct in behavior and attitude when dealing with people outside the organization but also within the organization (Xiao et al., 2020). Therefore, ethical business practices usually reflect patterns of behavior, beliefs, attitudes, and values of organizational culture. According to Abiodun and Oyeniyi (2014), behavior and especially business decisions can be considered ethical or unethical, depending on the actions and decisions that influence or change the parameters or values of companies in the environment in which they work, but also of people. Moreover, standards defined to be ethical cannot usually represent static ideals, rather they are representations of a dynamic nature in terms of human behavior. Obviously, the standards defined to be of an ethical nature reflect and implicitly represent the final piece of a clarification procedure but also the definition of the content and nature of human interaction.

When we identify the essential values of the company, it can help to develop some of them as values of special importance in that business and others being of ethical importance even if the differentiation cannot be special and also are business values are often correlated with ethical values. A segment of common values present in small and medium enterprises is presented in Table 1. Within these small and medium enterprises, the principles as well as the personal and professional values of managers and owners inevitably influence all these values.

Table 1. Business values and ethical values

\begin{tabular}{|c|c|}
\hline Business values & Ethical values \\
\hline Customer service & Integrity \\
\hline Quality & Honesty \\
\hline Innovation & Sincerity \\
\hline Trust & Respect \\
\hline Efficiency & Justice \\
\hline Value for money & Responsibility \\
\hline
\end{tabular}

Source: Adapted from Business Ethics Briefing, 2010, Institute of Business Ethics, London, no. Charity: 1084014, number 6, viewed January 12 June, 2020, at http://www.ibe.org.uk 8. The Significance of Business Ethics in SMEs.

It must be said that, nowadays, the power of the business environment is radically changed and moved from producers and sellers of products in markets with priority to buyers and consumers. When those stakeholders have authority over the business environment, they directly have influence over the markets and implicitly affect performance in terms of performance (Twomey and Jennings, 2011). Therefore, employees and business owners must exercise in good faith the practice by which they commit to make profits continuously. Companies that operate but do not take into account ethical values may have problems with business partners but also with employees, customers, the law (Putnam, 2016). As a consequence, the loss of business due to ethical behavior could be significant but also difficult to erase and the company's reputation will suffer. Once a business, by being unethical, has lost its reputation, customers will lose out to the competition and look for alternatives because they value ethical businesses (Donovan, 2013).

However, SMEs should be particularly careful to balance the values of society and individuals with the objectives of profits, practicing good business ethics (Twomey and Jennings, 2011). In conclusion, in order to survive, companies need good ethical values.

Socially responsible but also ethical practices generate long-term financial benefits for entrepreneurs. Consequently, the behavior associated with maintaining integrity and honesty, engaging in fair business practices, being trustworthy, accountable and accountable for one's actions are extremely important values and long-term actions for SMEs (Ahmad, 2009). According to Goll and Rasheed 
(2004), in surprising environments but also in those that are characterized by rapid changes, socially, ethically responsible behavior supports SMEs to gain support from various external stakeholder groups. SMEs have some protection against the unpredictability they face precisely because of such behavior. Therefore, the reputation and the image of a business are and can be influenced by the good practices they present to the general public and especially to customers (Jones, 2000). Gaining competitive advantage, through which a business distinguishes itself from its competitors, is also due to the benefits generated by good ethical practices (Ahmad et al., 2012). In fact, companies that are committed to strengthening integrity and high codes of ethics have much higher success rates when operating in a competitive environment, not only are they more competitive (Hasnah et al., 2015).

Given that some managers consider that the ethics programs in their organizations are only socially satisfactory and generally very expensive activities (McMurrian and Matulich, 2006), companies that are considered ethical (e.g., the public, suppliers, employees, customers) by their key factors have the opportunity to feel the benefits, including the particularly substantial involvement of employees, their loyalty but also greater efficiency in operations, as well as more competitiveness (Ferrell, 2004).

Consequently, all these special calibrations regarding organizational ethics make a particularly significant contribution in terms of performance but also the profitability of companies (McMurrian and Matulich, 2006).

It is therefore necessary for SMEs to appreciate the importance and especially the nature of business ethics in order to improve their overall reputation in the community and industry, to increase opportunities for performance, competitiveness and development, to minimize business failure.

Of course, under no circumstances can we lack the importance of ethics present in the business environment. Among the advantages that are generated by the acceptance and implementation of ethics in the business environment we can list:

- When making decisions, investors use values and business practices as the main considerations.

- Clients appreciate ethical practices because they are increasingly aware of their rights. Therefore, adopting ethics can help strengthen the reputation of businesses.

- Reputation promotion can help increase revenue and strengthen customer loyalty.

- Business performance is achieved by attracting a talented workforce which implicitly leads to increased employee productivity.

- Respects regulations such as the environment and labor laws.

- Collaboration with other companies both internationally and domestically.

According to Sraboni and Sharmistha (2011), a motivated but satisfied workforce is the first step towards long-term busi-ness success. Ethical practices towards employees can guarantee increased levels of employee motivation and thus job satisfaction, which leads to a better profitability of the business. In essence, voluntary investment in employee well-being, safety at work, a proactive approach to managing employee grievances.

\section{CHALLENGES}

Today, unethical behavior poses significant risks to business organizations and their stakeholders, which is indeed becoming prevalent in enterprises of all sizes (Borade, 2012). In terms of fraud, corruption and other unethical practices. Given to market products, limited funding sources, finances and dimensions. SMEs focus more on short-term survival and have no long-term vision.

Small and medium-sized enterprises are well aware of the size and extent of ethical practices that take place in government departments and large companies, which they consider an acceptable or standard practice. The gauge often influences the potential as well resources to avoid fraud and corruption in the business environment. In developing countries in particular, many tolerate fraud and corruption as acceptable and normal practices that they use as a means to do something faster, even when they know it is unethical and illegal (Rune, 2011). Enough companies face are forgery of expenses, breach 
of employee privacy, lying to stakeholders, discrimination, conflict of interest, internet abuse. , lying to employees, abusive behavior towards employees, abuse of company resources.

Table 2. Summary of challenges and ethical dilemmas faced by small and medium-sized enterprises

\begin{tabular}{|l|l|}
\hline Ethical dilemmas and challenges & Sources \\
\hline $\begin{array}{l}\text { Offering benefits to someone in business or } \\
\text { government to gain an inadequate market, job, or } \\
\text { economic advantage. }\end{array}$ & Abiodun \& Oyeniyi 2014 \\
\hline Corruption, bribery and fraud. & $\begin{array}{l}\text { Rune 2011; Unruh \& } \\
\text { Arreola 2009 }\end{array}$ \\
\hline Piracy and counterfeiting practices. & $\begin{array}{l}\text { Abiodun \& Oyeniyi 2014; } \\
\text { Rune 2011 }\end{array}$ \\
\hline $\begin{array}{l}\text { Searching for ethical schemes for accessing low } \\
\text { quality goods at lower prices and avoiding } \\
\text { taxation. }\end{array}$ & $\begin{array}{l}\text { Mahmood 2008; Tarus \& } \\
\text { Nganga 2013 }\end{array}$ \\
\hline $\begin{array}{l}\text { Fictitious expense accounts, which seek to } \\
\text { reimburse questionable or non-existent business } \\
\text { expenses, take over business goods or materials } \\
\text { for personal use, request or offer recoveries, and } \\
\text { fix prices. }\end{array}$ & Ononogbo si colab. 2016 \\
\hline $\begin{array}{l}\text { Bribery, coercion or intimidation, theft, } \\
\text { discrimination, fraud, harassment, dishonesty, } \\
\text { cover-up. }\end{array}$ & Botha 2012 \\
\hline $\begin{array}{l}\text { Abuse of company resources, abusive behavior } \\
\text { towards employees, lies for employees, Internet } \\
\text { abuse, conflict of interest, discrimination, lies for } \\
\text { stakeholders, abuse of employee benefits, breach } \\
\text { of employee confidentiality and falsification of } \\
\text { expenses. }\end{array}$ & Collins 2012 \\
\hline
\end{tabular}

\section{CONCLUSIONS}

Certainly, small and medium enterprises can no longer afford not to take into account business ethics. As a result of ethical practices, there are ongoing business failures, especially those associated with top executives and employees. In turn, this has negatively affected the survival and thus the reputation of SMEs, especially in developing countries.

As such, future researchers should conduct quantitative and qualitative empirical studies covering SMEs but also large companies internationally in terms of ethical dilemmas and business practices. It will inform both practitioners and researchers about the extent of the ethical practices of SMEs but also of large companies worldwide and the challenges they face.

It is not yet known whether the performance of new businesses benefits from entrepreneurial ethics and how they relate to each other. Entrepreneurial ethics has a "two-sided" impact on entrepreneurial performance, which is incorrect for the survival of new businesses, but which leads, in the long run, to their sustainable growth. The visibility of the company, as an institutional factor, plays a positive moderating role in the impact of entrepreneurial ethics on entrepreneurial performance. This conclusion confirms the usefulness of a good institutional environment and explores more advantageous factors to help ethics play an effective role in improving entrepreneurial performance, so as to provide suggestions to guide the implementation of the institution's ethical management. The researchers confirmed that business ethics and CSR have a different impact on performance in a different institutional environment. The visibility of companies has many antecedents, such as investments in advertising for companies, exposure in the media, the degree of market development, etc. 


\section{REFERENCES}

Abiodun, A. J. \& Oyeniyi, O. J. (2014). Ethical dilemmas in management: An African perspective. Journal of Business Systems, Governance and Ethics, 6(2), 36-44.

Ahmad, N. H. (2009). Doing well by doing good. A study of ethical and socially responsible practices among entrepreneurial ventures in an emerging economy. Frontiers of Entrepreneurship Research, 29(12), 1-15

Ahmad, N. H., Amran, A. \& Halim, H. A. (2012). Ethical and socially responsible practices among SME owner-managers: Proposing a multi-ethnic assessment. Journal of Southeast Asian Research, 43(2), 1-11.

Borade, G. (2012). Difference between ethics and morality. Buzzle. Retrieved May 17, 2020, from http://www.buzzle.com/articles/difference-between-ethics-and-morality.html.

Institute of Business Ethics. (2010). Business Ethics Briefing. London.

Ceptureanu, E., G. \& Ceptureanu, S., I. (2019a). The impact of adoptive management innovations on medium sized enterprises from a dynamic capability perspective. Technology Analysis \& Strategic Management, 31(10), 1137-1151. doi: 10.1080/09537325.2019.1587160.

Ceptureanu, E. G., Ceptureanu, S. I. \& Herteliu, C. (2019c). Evidence regarding external financing in manufacturing MSEs using Partial Least Squares regression. Annals of Operations Research, (volum si issue)1-14. doi: 10.1007/s10479-019-03291-2.

Donovan, A. M. (2013). The importance of business ethics to small ventures. Entrepreneurship and Innovation Management Journal, 1(1), 50-59.

Ferrell, O. C. (2004). Business ethics and customer satisfaction. Academy of Management Executive, 18(2), 126-129.

Goll, I. \& Rasheed, A. A. (2004). The moderating effect of environmental munificence and dynamism on the relationship between discretionary social responsibility and firm performance. Journal of Business Ethics, 49, 41-54.

Hasnah, H., Ishak, I. \& Sobei, O. (2015). Ethics, corporate social responsibility and the use of advisory services provided by SME: Lessons learnt from Japan. Asian Academy of Management Journal, 20(1), 71-100.

Hellriegel, D., Jackson, S. E., Slocum, J., Staude, G., Amos, T., Klopper, H. B. et al. (2008). Management, 3rd South African edn. Cape Town: Oxford University Press,.

Herteliu, C., Jianu, I., Bobb, V. S., Dhesi, G., Ceptureanu, S. I., Ceptureanu, E. G. Et al. (2019). Money's importance from the religious perspective. Annals Of Operations Research, doi: 10.1007/s10479-019-03488-5.

Jones, J. (2000). Ethics revisited. The 1990s: An "ethical decade” or a decade of hypocrisy? Adelaide: Flinders University.

McMurrian, R. C. \& Matulich, E. (2006). Building customer value and profitability with business ethics. Journal of Business \& Economics Research, 4(11), 11-18.

Putnam, M. S. (2016). Ethical values for business success. Bothel: Global Ethics University.

Riley, J. (2012). Introduction to business ethics. Tutor2U. Retrieved February 18, 2020, from http:// www.tutor2u.net/business/strategy/business-ethics-introduction.html.

Rossouw, R. (2004). Business ethics, 3rd edn. Cape Town: Oxford University Press.

Rune, A. (2011). Corruption and SMEs: Exploring the business case for western SMEs to counter involvement in administrative corruption in developing countries. Master's thesis. Copenhagen Business School, Business and Development Studies, Frederiksberg, Denmark.

Spence, E. \& Van Heekeren, B. (2005). Advertising ethics. Upper Saddle River: Pearson Education Inc. 
Sraboni, D. \& Sharmistha, B. (2011). Ethical practices towards employees in small enterprises: A quantitative index. International Journal of Business Management and Economic Research, 2(3), 205-221.

Twomey, D. P. \& Jennings, M. M. (2011). Anderson's business law and the legal environment, 21st edn. Mason: South-Western Cengage Learning.

Xiao, L., Dhesi, G., Ceptureanu, E. G., Lin, K., Herteliu, H., Syed, B. et al. (2020). Liquidity transmission and the subprime mortgage crisis: a multivariate GARCH approach. Soft Computing, 24, 13871-13878. doi:10.1007/s00500-020-04772-4. 